\title{
SCMT4
}

Las Vegas, USA, August7-11, 2016

\section{Effect of Perlite Powder on Durability Properties of Concrete Under Chloride Attack}

\author{
Ali Akbar Ramezanianpour ${ }^{1}$, Seyed Mahmoud Motahari Karein ${ }^{2 a *}$, Amir Reza Pilvar ${ }^{2 b}$, \\ Faramarz Moodi ${ }^{2 c}$ \\ ${ }^{1}$ Head of Concrete Technology and Durability Research Center (CTDRc), Amirkabir University of \\ Technology,Tehran,Iran, ${ }^{1}$ Email: <aaramce@aut.ac.ir>. \\ ${ }^{2}$ Concrete Technology and Durability Research Center (CTDRc), Amirkabir University of Technology, \\ Tehran,Iran. ${ }^{2 a}$ Email: <mahmoud.motahari@aut.ac.ir>, ${ }^{2 b}$ Email:<amir.pilvar@aut.ac.ir>, \\ ${ }^{2 c}$ Email: $\langle f . m o o d i @ a u t . a c . i r\rangle$.
}

\begin{abstract}
The use of Supplementary Cementitious Materials (SCMs) has been developed to reduce the environmental pollution and the consumption of precious natural resources in the concrete industries. Furthermore, use of these materials usually reduces the cost and enhances the durability of concrete. Perlite, as a natural glassy volcanic rock, is easily accessible in the most parts of the world; besides, previous studies have demonstrated that Calcined Perlite Powder(CPP) could be used as an effective SCM. However, few studies have investigated the impact of it on different properties of concrete. In this study, the influence of partial replacement of Ordinary Portland Cement (OPC) with CPP on the compressive strength and concrete resistance to chloride ions ingress is investigated. For this purpose, eight different concretes by two w/b ratios and three levels of OPC replacement were cast, cured, and tested at 7,28 and 91 days.

Results reveal that although replacement of OPC with CPP insignificantly decreases the compressive strength of concrete, the permeability is highly improved. Besides, it was known that surface resistivity as a simple non-destructive test, even in concretes containing CPP, could reliably predict the rapid chloride permeability and the migration coefficient of concrete.
\end{abstract}

\section{INTRODUCTION}

It is currently well known that using supplementary cementitious materials (SCMs) is imperative for both producing high performance concrete and preserving the environment. Concrete industry, indeed, is one of the major consumers of natural resources and producers of greenhouse gases all around the world, mainly as a result of manufacturing clinker (Ramezanianpour, 2013 and Valipour et al., 2014). Therefore, each choice resulting in decline in consumption of Ordinary Portland Cement (OPC) should be taken into account if it provides minimum requirements for fresh and hardened concrete. Thus, there are strong demands to investigate assorted substances for replacing a part of Portland clinker.

Perlite, as a natural glassy volcanic rock, is easily accessible in the most parts of the world. In fact, it is estimated that there are about 6700 million tons of perlite reserves all around the world (Erdem et al., 2007). 
Previously, expanded perlite, mainly because of its lightness, thermal and acoustic insulation properties was employed as lightweight aggregate in the construction industry (Demirboğa et al., 2001, Singh and Garg, 1991 and Bektas et al., 2005). However, according to the former studies (Erdem et al., 2007), perlite powder has an amorphous siliceous nature and conforms to all specifications of ASTM C618 (2012); consequently, it probably could be used as a beneficial SCM. Nevertheless, there are few studies on how it affects the main characteristics of fresh and hardened concrete in different replacement levels.

Erdem et al. (2007) demonstrated that replacing OPC with perlite powder in 20 and 30 percent (by weight of OPC) leads to rising water demand of normal consistent paste, initial and final setting time. Furthermore, $\mathrm{Yu}$ et al. (2003) investigated effects of replacement percentage, age, fineness, and w/c ratio on the pozzolanic reaction of perlite powder by studying the concrete compressive strength. They found that the optimum replacement percentage of OPC with perlite powder is equal to 15 and 20 percent for the strength at 28 and 91 days, respectively.It was also demonstrated that perlite powder of which only $5.6 \%$ remains on the $80-\mu \mathrm{m}$ sieve had the highest activity. In addition, they detected perlite powder has a greater contribution to the improvement of compressive strength at higher w/c ratio (Yu et al., 2003). Moreover, Bektas et al. (2005) investigated the influence of calcined and natural Perlite powder in suppressing the expansion resulting from Alkali-Silica Reaction (ASR). They found that although both of them can effectively limit the expansion of mortars, Calcined Perlite Powder (CPP) is more effective.

SCMs, at a proper level of replacing with OPC, generally reduce porosity, mean pore size, and pore diameter of microstructure of cement paste (Johari et al., 2011). Yu et al. (2010) studied the influence of perlite powder as an admixture on the pore structure of cement pastes. Their study demonstrated that due to the pozzolanic reactions, it could diminish porosity and pores diameter in cement pastes. Furthermore, SCMs could generally inhibit reinforcement corrosion by increasing chloride binding (Lu et al., 2002), decreasing chloride permeability (Thomas and Bamforth, 1999), boosting threshold chloride content (Manera et al., 2008), and/or modifying the pore volume, size and connectivity of concrete matrix (Yang and Cho, 2003 and Khan, 2010).

In this study, influence of utilizing CPP as a SCM on the compressive strength and chloride penetration resistance of concrete is investigated. For this purpose, eight different concretes by two w/b ratios and three levels of replacing OPC were casted, cured, and tested at 7, 28 and 91 days. In addition to the compressive strength test, surface resistivity, Rapid Chloride Permeability (RCP), and Rapid Chloride Migration (RCM) tests were carried out to show the effects of CPP over the permeability of concrete. Finally, results of these experiments are compared to each other in order to study their relationships and possibility of prediction of RCP and chloride migration coefficient of concrete by its surface resistivity, as a non-destructive, simple, and inexpensive test.

\section{EXPERIMENTAL PROGRAM}

\section{Materials}

Type 1 Portland cement conforming to the requirements of ASTM C150 was used in this study for all of the concrete mixtures. Crushed Perlite rocks were calcined for one hour at a temperature of $850^{\circ} \mathrm{C}$; then, they were ground to reach the same fineness as that of OPC. Chemical and physical characteristics of both OPC and CPP are demonstrated in Table 1. As it can be seen, the summation of $\mathrm{SiO}_{2}, \mathrm{Al}_{2} \mathrm{O}_{3}$ and $\mathrm{Fe}_{2} \mathrm{O}_{3}$ is equal to $88.48 \%$ which exceeds the minimum required level of calcined natural pozzolans defined in ASTM 
C618. Besides, strength activity indexes at 7 and 28 days show that although substituting $20 \%$ of OPC with CPP leads to decreased the compressive strength of mortar, this reduction is less than the maximum permitted range based on ASTM C618.

Table 1. Chemical and physical characteristics of OPC and CPP

\begin{tabular}{|c|c|c|c|c|}
\hline \multicolumn{3}{|c|}{ Chemical Composition* $(\%)$} & OPC & CPP \\
\hline \multicolumn{3}{|c|}{$\mathrm{CaO}$} & 65.3 & 2.24 \\
\hline \multicolumn{3}{|c|}{$\mathrm{SiO}_{2}$} & 20.8 & 72.62 \\
\hline \multicolumn{3}{|c|}{$\mathrm{Al}_{2} \mathrm{O}_{3}$} & 4.3 & 14.32 \\
\hline \multicolumn{3}{|c|}{$\mathrm{Fe}_{2} \mathrm{O}_{3}$} & 2.2 & 1.54 \\
\hline \multicolumn{3}{|c|}{ MgO } & 2.17 & 0.82 \\
\hline \multicolumn{3}{|c|}{$\mathbf{K}_{2} \mathbf{O}$} & 0.63 & 4.90 \\
\hline \multicolumn{3}{|c|}{$\mathrm{Na}_{2} \mathrm{O}$} & 0.36 & 2.85 \\
\hline \multicolumn{3}{|c|}{ Loss on ignition (\%) } & 0.91 & 2.67 \\
\hline \multicolumn{3}{|c|}{ Specific gravity } & 3.15 & 2.87 \\
\hline \multirow{3}{*}{$\begin{array}{l}\text { Physical } \\
\text { properties }\end{array}$} & \multicolumn{2}{|c|}{ Fineness $* *\left(\mathrm{~cm}^{2} / \mathrm{g}\right)$} & 2800 & 3100 \\
\hline & \multirow{2}{*}{$\begin{array}{l}\text { Strength activity } \\
\text { index } x^{* * *}\end{array}$} & 7 days & - & 77 \\
\hline & & 28 days & - & 81 \\
\hline
\end{tabular}

* Chemical Composition is specified according to ASTM C114

** Fineness is determined by blaine apparatus based on ASTM C204

*** Strength activity index is determined based on ASTM C311 by substituting $20 \%$ of OPC with CPP

The fine aggregate used was natural river sand with fineness modulus of 2.95; its specific gravity and water absorption were equal to 2.56 and $1.82 \%$, respectively. Furthermore, coarse aggregate were made up of crushed calcareous aggregate with $19 \mathrm{~mm}$ nominal maximum size, 2.58 specific gravity and $1.61 \%$ water absorption. Both aggregates were in compliance with the requirement of ASTM C33.

Potable water was used for casting and curing of all the specimens. Also, the PolycarboxylateEther (PCE) based superplasticizer with specific gravity of 1.05 , solids content of $28 \%$ and $\mathrm{pH}$ of 6.6 was employed to achieve relatively constant workability.

\section{Specimens preparation}

Eight different concrete mixtures were designed by two water/binder ratios $(0.35$, and 0.45$)$ and three replacement percentage levels of CPP $(10,20$, and $30 \%$ by mass of OPC); besides, all the mixtures have constant total binder content of $350 \mathrm{~kg} / \mathrm{m}^{3}$. Further details of the mixture proportions are demonstrated in Table 2.

Slump of all the mixtures, as an indicator of their workability, were kept constant in the range of $90 \pm 10$ mm using adequate amount of the super plasticizer (see Table 2). As it is clear in the table, higher amount of super plasticizer was required to recoup the effect of replacement OPC with CPP in a higher level and gain desire slump. 
All the specimens were casted in two layers; each layer was consolidated on a vibrating table to reduce the air voids. Then, the specimens were kept under a wet towel in the laboratory for 24 hours. After that, they were demolded and cured in lime-saturated water at $23 \pm 2{ }^{\circ} \mathrm{C}$ until the test day to impede possible leaching of $\mathrm{Ca}(\mathrm{OH})_{2}$ from these specimens.

Table 2. Mix proportion of concretes

\begin{tabular}{|c|c|c|c|c|c|c|c|c|}
\hline \multirow{2}{*}{ Mix } & \multirow{2}{*}{ W/b } & \multicolumn{2}{|c|}{ Perlite } & \multirow{2}{*}{$\begin{array}{c}\text { Cement } \\
\end{array}$} & & $\mathbf{( \% )}$ & $\begin{array}{c}\text { Water } \\
\left(\mathbf{k g} / \mathbf{m}^{\mathbf{3}}\right)\end{array}$ & \multicolumn{2}{|c|}{ Aggregate $\left(\mathrm{kg} / \mathrm{m}^{3}\right)$} & \multirow{2}{*}{$\begin{array}{c}\text { HRWRA* } \\
\left(\mathbf{k g} / \mathrm{m}^{3}\right)\end{array}$} & Coarse & Fine & $(\%)$ \\
\hline P4500 & 0.45 & 0 & 0 & 350 & 157.5 & 712 & 1043 & 0.00 \\
\hline P4510 & 0.45 & 10 & 35 & 315 & 157.5 & 712 & 1043 & 0.10 \\
\hline P4520 & 0.45 & 20 & 70 & 280 & 157.5 & 712 & 1043 & 0.15 \\
\hline P4530 & 0.45 & 30 & 105 & 245 & 157.5 & 712 & 1043 & 0.42 \\
\hline P3500 & 0.35 & 0 & 0 & 350 & 122.5 & 754 & 1131 & 0.54 \\
\hline P3510 & 0.35 & 10 & 35 & 315 & 122.5 & 754 & 1131 & 0.72 \\
\hline P3520 & 0.35 & 20 & 70 & 280 & 122.5 & 754 & 1131 & 0.90 \\
\hline P3530 & 0.35 & 30 & 105 & 245 & 122.5 & 754 & 1131 & 1.11 \\
\hline
\end{tabular}

* Super Plasticizer percentage is presented by Portland cement mass

\section{Test methods}

\section{Compressive strength}

Three $100 \mathrm{~mm}$ cubic specimens of every mixture were tested at 7, 28 and 91 days to evaluate effects of using CPP as a SCM on this parameter. The average of three test results for every mixture is reported at each test age.

\section{Surface Electrical Resistivity (SR)}

In 1915, Wenner (1915) proposed a practical method to investigate characteristics of the earth by its surface electrical resistivity. Then, this test is adopted and standardized later by FDOT (2004) and AASHTO (2011) for concrete specimens. This method, as a non-destructive, fast, simple, inexpensive and reliable test (Robert et al., 2011) is being used to assess the permeability of concrete (Ramezanianpour et al., 2011). It must be pointed out that the results of SR tests are affected by the chemical composition of the pore solution (Streicher et al., 1995). This can influence the results of applying these methods in studying concrete samples with supplementary cementitious materials, due to the low concentration of $\mathrm{OH}$ - ions in their pore solution.

In this study, at the age of 7, 28 and 91 days, surface resistivity of three $100 \times 200 \mathrm{~mm}$ cylindrical specimens were measured via a four-point Wenner array probe. The probe spacing was set to $38.1 \mathrm{~mm}$ during the test. Eight measurements were conducted on each specimens and the mean of three specimens' result is reported.

\section{Rapid Chloride Permeability Test (RCPT)}

The most frequently accelerated test to evaluate concrete resistance to chloride ions ingress is RCP test. This test firstly proposed by Whiting (1981) to predict diffusion coefficient of concrete determined by salt 
ponding test (2002) which is time-consuming and costly. In fact, RCPT indirectly appraises the concrete permeability by measuring the charge passed through the specimen as a result of applied electrical gradient during the test. This test method is standardized by ASTM C1202 (2012) and AASHTO T277 (2007).

In this study, at the each age of 28 and 91 days, three $50 \mathrm{~mm}$ thick slices were cut from the middle part of $100 \times 200 \mathrm{~mm}$ cylindrical specimens of each mixture. After standard preparation and assembling the slices in test cells, a direct current (DC) by a constant $60 \mathrm{~V}$ potential difference was applied to them for a six-hour period. Simultaneously, by monitoring the current flowing through the slices every 5 minutes, the total passed charge was calculated via time integration. The average of three test results is used to minimize the discrepancy of RCPT results.

\section{Rapid Chloride Migration Test (RCMT)}

Tang and Nilsson (1993) proposed RCM test to evaluate the chloride penetration resistance of concrete without the main problems of RCPT (Bagheri and Zanganeh, 2012). Migration coefficient of concrete is not affected by using different SCMs or conductive admixtures (Stanis et al., 2005). Furthermore, the specimen does not experience rising temperature, and this test method is more reliable than RCPT (Stanis et al., 2001). Both AASHTO (2003) and NORDTEST (2003) standardized this method. In this study, RCMT was conducted at the age of 28 and 91 days in compliance with NORDTEST by specimens similar to RCPT.

\section{RESULTS and DISCUSSION}

\section{Compressive strength}

The compressive strength of the mixtures at three ages of 7, 28 and 91 days are demonstrated in figure 1. As it is expected, it shows compressive strength of all the specimens increases over the time; also, the mean compressive strength of the mixtures increases for longer curing periods and lower w/b ratios. Furthermore, as seen in the figure, substitution of OPC with CPP even up to $30 \%$ does not lead to a significant reduction in the compressive strength at the age of 91 days. Indeed, its maximum reduction is limited to 12 and 8 percent (7.8 and 3.7 $\mathrm{MPa}$ ) for mixtures with w/b equal to 0.35 and 0.45 , respectively.

SCMs affect the compressive strength of concrete by three main factors: (a) the filling effect, (b) the dilution effect, and (c) the pozzolanic reaction (Wild et al., 1996). Based on the results, it could be inferred that at all the replacement levels, dilution is the dominant effect and concrete containing CPP cannot reach the compressive strength of the control mixtures; however, at 10 percent substitution and 91-day age this diminution is minimized due to the positive effects of pozzolanic reaction and filling effect.

Furthermore, the positive effect of CPP over the compressive strength of concrete is more remarkable on the mixtures with $w / b=0.45$ than those of $w / b=0.35$; therefore, compressive strength reduction in these mixtures is lower. In fact, there is more porous space in these mixtures which leads to lower density and compressive strength. However, these spaces simultaneously provide suitable place for nucleus generation and development of pozzolanic reaction around them in concrete containing SCMs. Therefore, products of pozzolanic reaction can fill these spaces; as a result, this reaction has more important positive effect in porous concrete than the concretes with low w/b. 


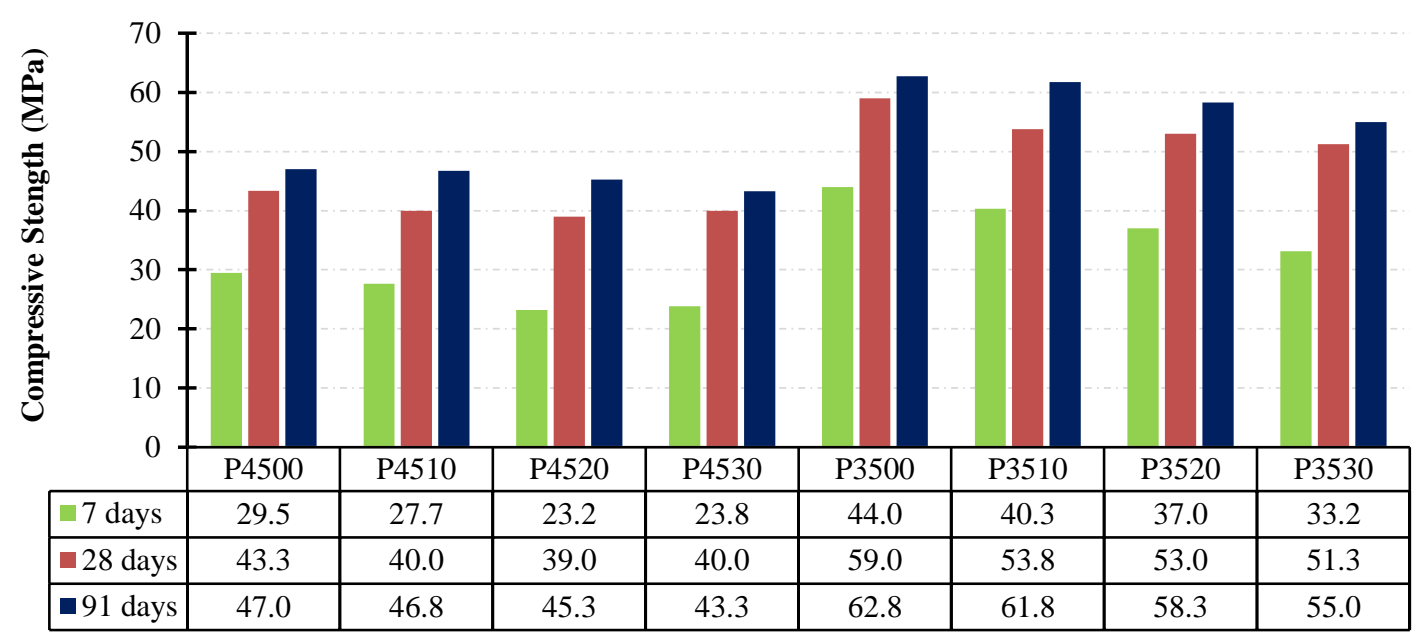

Figure 1. The effect of perlite powder on the compressive strength

\section{Surface Electrical Resistivity (SR)}

Concrete resistivity is reliant on both the pore structure and the pore solution chemistry. Indeed, it represents mobility of ions in concrete, so it can be a suitable indicator for chloride penetration resistance of concrete. Besides, low conductive concrete impedes movement of ions from anodic to cathodic regions during the procedure of reinforcement corrosion (Ramezanianpour et al., 2012), so it also can be an index of corrosion rate (Valipour et al., 2014).

The results of surface resistivity test are shown in figure 2. They depict that in each group of specimens with equal w/b, surface resistivity of control mixture is slightly higher than that of pozzolanic concretes at the age of 7 days. Indeed, due to low pozzolanic activity at early age, the mixtures with higher OPC content have lower porosity and conductivity. On the other hand, replacing OPC with CPP of different levels leads to an increase in the surface resistivity up to two times at 28 days. Probably, dilution effect and pozzolanic reactions are the main reasons. In fact, substitution of OPC causes reduction in the amount of available ions in the pore solution, and pozzolanic reactions can also intensify this occurrence.

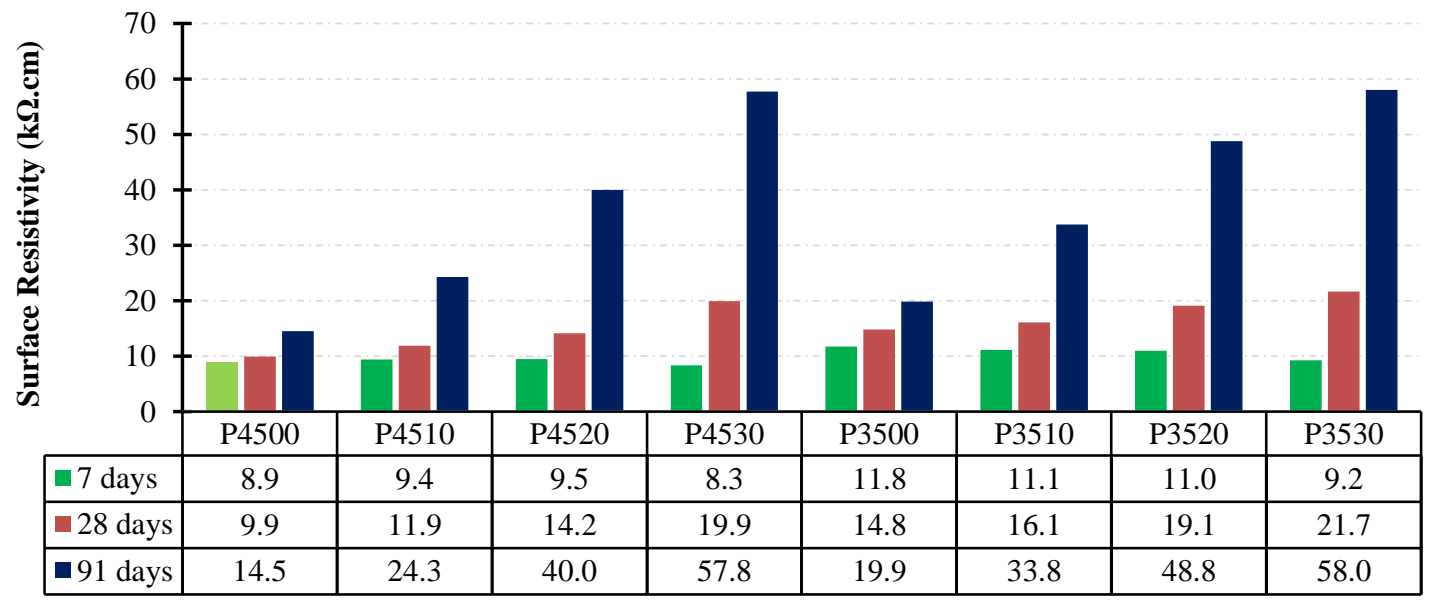

Figure 2. The effect of perlite powder on the surface electrical resistivity 
Furthermore, at the age of 91 days, this increment is more sharply up to four times in comparison with the control mixtures. It seems that, in addition to dilution effect, the main reason of this great increase is the pozzolanic reaction which can result in the reduction of the conductivity of pore solution. $\mathrm{OH}^{-}$ions being consumed in this reaction are the most conductive ions in the pore solution of concrete (Shi et al., 1998); consequently, by their consumption, the concrete resistivity is strongly increased. This severe difference between the surface resistivity of the mixtures at the age of 28 and 91 days shows that the main part of pozzolanic reaction of CPP has probably occurred after the age of 28 days.

In addition, based upon the chloride ion permeability classes presented in Table 3, it is evident that at 28day age, utilizing CPP improves the concrete permeability class from high to moderate, and moderate to low, respectively for the control mixture with w/b ratios equal to 0.45 and 0.35 .

Table 3. Chloride ion permeability classes according to $\mathrm{RCP}$ and surface resistivity test

\begin{tabular}{|c|c|c|}
\hline Chloride ion permeability & $\begin{array}{c}\text { Surface } \\
\text { resistivity }(\mathrm{k} \Omega . \mathrm{cm})\end{array}$ & $\begin{array}{c}\text { Rapid Chloride Permeability } \\
\text { (Coulombs) }\end{array}$ \\
\hline High & $<12$ & $>4000$ \\
\hline Moderate & $12-21$ & $2000-4000$ \\
\hline Low & $21-37$ & $1000-2000$ \\
\hline Very low & $37-254$ & $<100-1000$ \\
\hline Negligible & $>254$ & $<100$ \\
\hline
\end{tabular}

By comparison of how substitution of CPP by OPC influences the strength and conductivity of the concretes, it can be concluded that although pozzolanic reaction products interrupt the connectivity of porous spaces, they cannot effectively reduce the porosity of the mixtures. Indeed, compressive strength of a definite type of concrete directly related to its density and porosity; as it is described, none of the mixtures could even reach the strength of the control mixtures. Nevertheless, the permeability of the concrete is sharply reduced as it is clarified in this section.

\section{Rapid Chloride Permeability Test (RCPT)}

This test method, in fact, measures the electrical charge passed through the slice specimen during the test as an indication of its permeability. As it is expected, duo to the resistivity of concrete, passing this electrical current increased the temperature of specimens, especially this was remarkable for more permeable ones. RCP results of all the mixtures are indicated in figure 3. The results show that substitution of OPC with CPPhas improved the concrete impermeability of the mixtures similar to the surface resistivity.

This substitution decreases the RCP of the mixture with half at 28 days; nevertheless, at the age of 91 days, it sharply decreases to less than one fifth. This reduction is more strongly than that of conductivity which is represented by surface resistivity test. Besides, the rate of reduction of the charge passed through the slices with $w / b=0.35$, at different levels of replacement, is much lower than that of specimens in which $w / b$ is equal to 0.45 . For instance, at the age of 91 days, although $\mathrm{RCP}$ of the control mixture with w/b=0.45 decreases to lower than one-fifth by substitution of 30 percent of OPC, that of mixture with $w / b=0.35$ only 
decreases to more than a forth at the same replacement level. Mainly, the inherent problem of RCPT which underestimates the permeability of the porous concrete (Ramezanianpour et al., 2011 and Betancourt and Hooton, 2004) might be the underlying reason of these differences.

Furthermore, according to the classification of 28-day chloride ion permeability in Table 3, although all the mixtures with $w / b=0.35$ are in the moderate permeability class, replacement of 30 percent of OPC with CPP improves the permeability class of control mixture with w/b of 0.45 from high to moderate class.

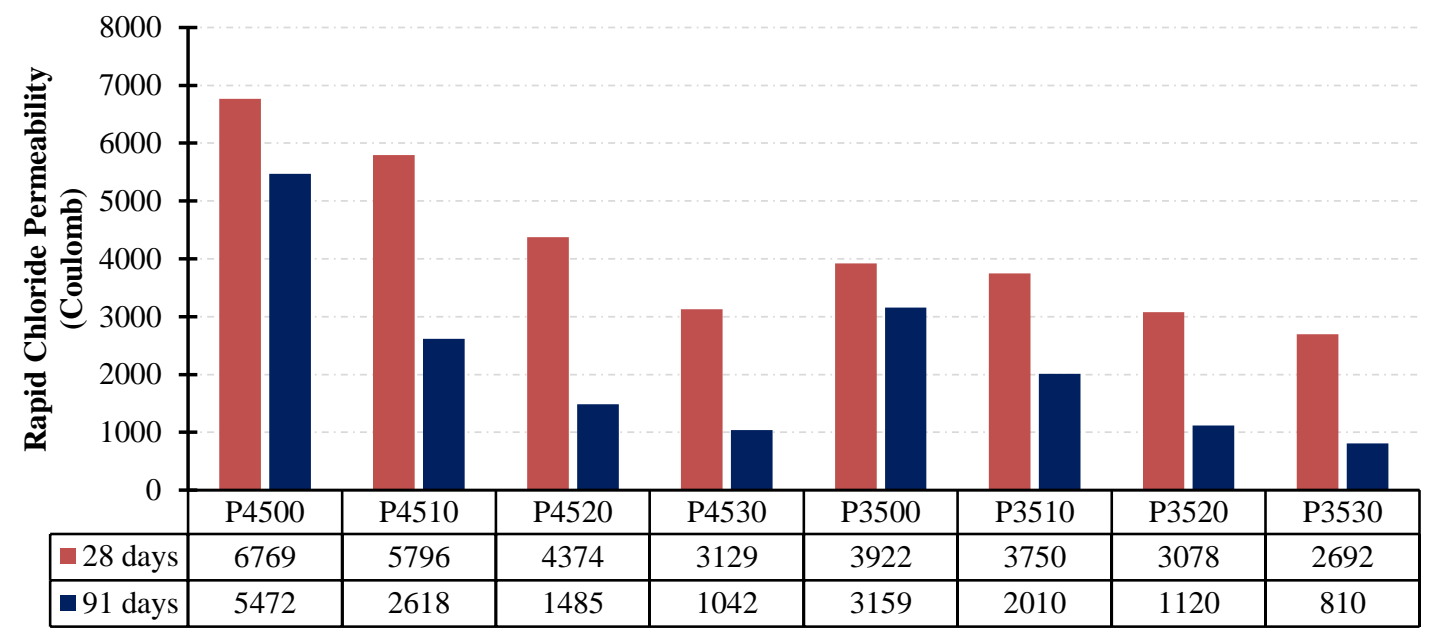

Figure 3. The effect of perlite powder on the rapid chloride ions permeability

\section{Rapid Chloride Migration Test (RCMT)}

Contrary to surface resistivity and RCP tests, depth of the chloride penetration is directly measured in RCMT, so it seems that its results is fundamentally more appropriate to assess the chloride ions permeability, especially in the concrete containing SCMs. According to the equations presented in the NORDTEST standard method (1999), non-steady-state chloride migration coefficient $\left(\mathrm{D}_{\mathrm{nssm}}\right)$ is calculated using the applied potential difference, time and chloride penetration depth of the specimens in the test. All the results are demonstrated in figure 4.

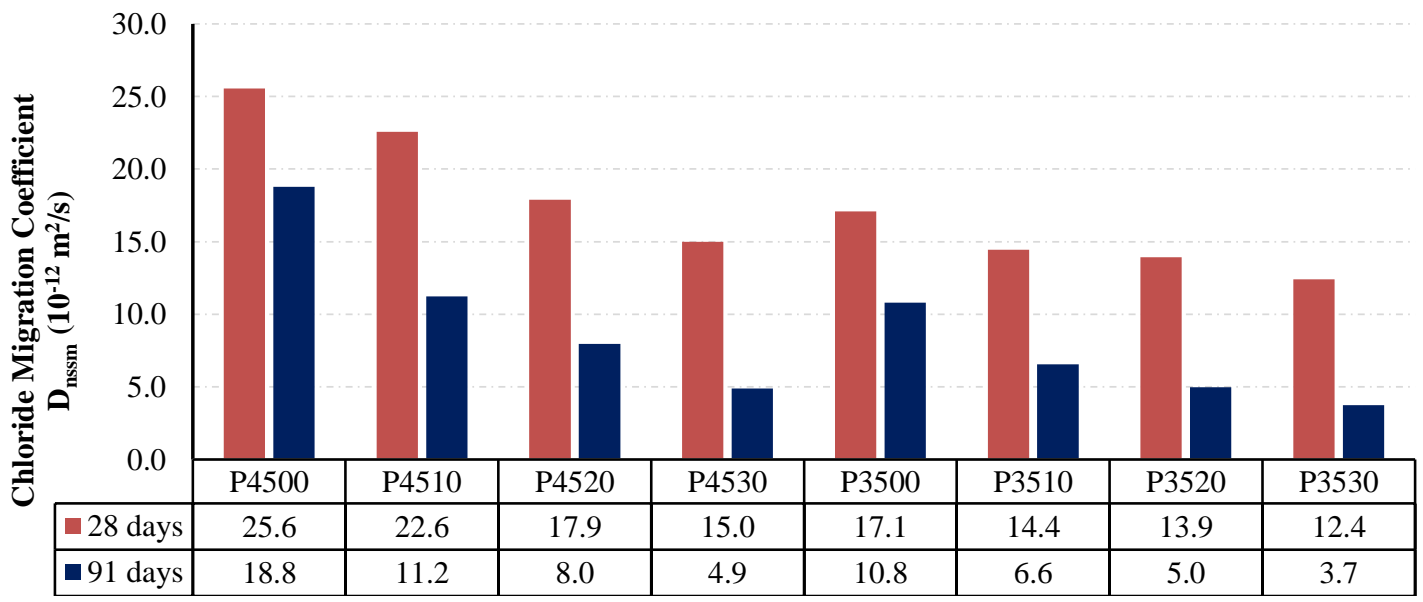

Figure 4. The effect of perlite powder on the non-steady-state chloride migration coefficient 
As it is expected, the general trend of the results is similar to surface resistivity and RCP. The results show that generally, the mixtures with $w / b=0.45$ have a greater migration coefficient than that of with $w / b$ equal to 0.35 . Furthermore, it is clear that reduction in the permeability of concrete with $w / b=0.45$ is more intensive than that of $w / b=0.35$. For instance, although the migration coefficient of the mixture with $\mathrm{w} / \mathrm{b}=0.45$ and 30 percent $\mathrm{OPC}$ substitution at the age of 91 days is about 26 percent of the control mixture, that of the same mixture with $w / b=0.35$ is only about 34 percent of control mixture.

\section{CONCLUSION}

Replacement a part of OPC with SCMs is a convenient choice leading to a reduction in the consumption of the precious natural resources, pollution of the environmental and the cost of the concrete production; simultaneously, these materials typically improve the durability of concrete. This study demonstrates that Calcined Perlite Powder (CPP) can be considered as a suitableSupplementary Cementitious Material (SCM). Furthermore, the main conclusions which could be drawn from this study are as follows:

a) CPP decreases the workability of concrete, so it should be used with adequate quantity of HRWRA to have a relatively constant slump.

b) Replacing a part of Ordinary Portland Cement (OPC) with CPP leads to an insignificant reductionin the compressive strength of the concrete. This reduction is between 12 and 8 percent for the concrete with $30 \%$ replacement and at $\mathrm{w} / \mathrm{b}$ between 0.35 and 0.45 .

c) Utilizing $\mathrm{CPP}$ as a SCM reduces conductivity of the pore solution by consumption of the lime in the pozzolanic reactions.

d) The main parts of pozzolanic reaction of CPP occurs after 28 days, so the surface resistivity, rapid chloride permeability, and chloride migration coefficient of concrete strongly improved at the age of 91 days in comparison with 28 days.

e) CPP is more effective to improve the properties of the control mixture with w/b of 0.45 rather than $\mathrm{w} / \mathrm{b}$ of 0.35 . Indeed, in the permeable concrete, the influence of SCMs such as CPP over the reduction of the porosity, diameter, and connectivity of pores by producing further C-S-H gel is more remarkable.

\section{REFERENCES}

AASHTO, "Standard Method of Test for Predicting Chloride Penetration of Hydraulic Cement Concrete" by the Rapid Migration Procedure, in AASHTO TP064, (2003), American Association of State and Highway Transportation Officials: Washington DC, USA.

AASHTO, "Standard Method of Test for resistance of concrete to chloride ion penetration", in AASHTO T259, (2002), American Association of State and Highway Transportation Officials: Washington DC, USA.

AASHTO, "Standard Method of Test for Electrical Indication of Concrete's Ability to Resist Chloride Ion Penetration", in AASHTO T277, (2007), American Association of State and Highway Transportation Officials: Washington DC, USA.

AASHTO, "Standard Method of Test for Surface Resistivity Indication of Concrete's Ability to Resist Chloride Ion Penetration", in AASHTO TP095, (2011), American Association of State Highway and Transportation Officials Washington DC, USA. 
ASTM International, "Standard Specification for Coal Fly Ash and Raw or Calcined Natural Pozzolan for Use in Concrete", in ASTM Standard C618, (2012), American Society for Testing and Materials: West Conshohocken.

ASTM International, "Standard Test Method for Electrical Indication of Concretes Ability to Resist Chloride Ion Penetration", in ASTM Standard C1202, (2012), American Society for Testing and Materials: West Conshohocken.

Alexander, M.G., A. Bertron, and N. De. (2013). "Performance of Cement-based Materials in Aggressive Aqueous Environments", Vol. 10. Springer.

Bagheri, A. R., and Zanganeh, H. (2012), "Comparison of Rapid Tests for Evaluation of Chloride Resistance of Concretes with Supplementary Cementitious Materials", Journal of Materials in Civil Engineering. 24(9): p. 1175-1182.

Bektas, F. , Turanli, L. and Monteiro, P. J. M. (2005). "Use of perlite powder to suppress the alkali-silica reaction", Cement and Concrete Research,. 35(10): p. 2014-2017.

Betancourt, G. A. J., and Hooton, R. D. (2004). "Study of the Joule effect on rapid chloride permeability values and evaluation of related electrical properties of concretes", Cement and Concrete Research,. 34(6): p. 1007-1015.

Demirboğa, R, Örüng, İ and Gül, R. (2001). "Effects of expanded perlite aggregate and mineral admixtures on the compressive strength of low-density concretes", Cement and Concrete Research,. 31(11): p. 16271632.

Erdem, T. K, Meral, Tokyay, C. M. and Erdoğan, T. Y. (2007). "Use of perlite as a pozzolanic addition in producing blended cements", Cement and Concrete Composites, 29(1): p. 13-21.

FDOT, FM 5-578: "Florida Method of Test for Concrete Resistivity as an Electrical Indicator of its Permeability, in Florida Department of Transportation", 2004: Florida, USA.

Frank Wenner, F. (1915). "A method of measuring earth resistivity. Bulletin of the Bureau of Standards", 12(12): p. 469-478.

Johari, M. A. M. et al. (2011). "Influence of supplementary cementitious materials on engineering properties of high strength concrete", Construction and Building Materials, 25(5): p. 2639-2648.

Khan, M.I. (2010). "Nanostructure and microstructure of cement concrete incorporating multicementitious composites", Transportation Research Record: Journal of the Transportation Research Board,. 2141(1): p. 21-27.

Luping, T., and Nilsson,L. O. (1993). "Rapid determination of the chloride diffusivity in concrete by applying an electric field", ACI Materials Journal,. 89(1).

Manera, M., Vennesland, Q., and Bertolini, L. (2008). "Chloride threshold for rebar corrosion in concrete with addition of silica fume", Corrosion Science,. 50(2): p. 554-560.

NORDTEST, Concrete, mortar and cement-based repair materials: "chloride migration coefficient from non-steady-state migration experiments", in NT BUILD 492 Approved 1999-11.

Ramezanianpour, A.A., Pilvar, A., Mahdikhani,M., and Moodi, F. (2011). "Practical evaluation of relationship between concrete resistivity, water penetration, rapid chloride penetration and compressive strength", Construction and Building Materials,. 25(5): p. 2472-2479.

Ramezanianpour, A. A., Kazemian, A., Sarvari, M., and Ahmadi, B. (2012). "Use of natural zeolite to produce Self-consolidating concrete with low portland cement content and high durability", Journal of Materials in Civil Engineering,. 25(5): p. 589-596. 
Ramezanianpour, A. A. (2013). "Cement Replacement Materials: Properties, Durability, Sustainability", Springer London, Limited.

Robert P. S, Castro, J. ,Nantung, T E. , Paredes, M. and William J. W. (2011). "Variability analysis of the bulk resistivity measured using concrete cylinders", in Final Report No. FHWA/IN/JTRP-2011/21.

Shi, C., Stegemann, J. A., and Caldwell, R. J. (1998). "Effect of supplementary cementing materials on the specific conductivity of pore solution and its implications on the rapid chloride permeability test", (AASHTO T277 and ASTM C1202) results. ACI Materials Journal,. 95(4).

Singh, M and Garg, M. (1991). "Perlite-based building materials - a review of current applications", Construction and Building Materials. 5(2): p. 75-81.

Stanish, K., Hooton, R. D., and Thomas, M. DA. (2001). "Prediction of chloride penetration in concrete", in FHWA-RD-00-142, US Department of Transportation, Federal Highway Administration: Washington, DC.

Stanish, K., Hooton, R. D., and Thomas, M. DA. (2005). "The Rapid Migration Test for HPC", HPC Bridge Views, (37): p. Portland Cement Association, Federal Highway Administration, National Concrete Bridge Council.

Streicher, P.E. and Alexander, M.G. (1995). " A Chloride Conduction Test for Concrete", Cement and Concrete Research, Vol. 25, No. 6, pp. 1284-1294.

Thomas, M.D.A. and Bamforth, P.B. (1999). "Modeling chloride diffusion in concrete: Effect of fly ash and slag", Cement and Concrete Research,. 29(4): p. 487-495.

Valipour, M., Shekarchi, M., and Ghods, P. (2014). "Comparative studies of experimental and numerical techniques in measurement of corrosion rate and time-to-corrosion-initiation of rebar in concrete in marine environments", Cement and Concrete Composites,. 48(0): p. 98-107.

Valipour, M. Yekkalar, M., Shekarchi, M. and Panahi, S. (2014). "Environmental assessment of green concrete containing natural zeolite on the global warming index in marine environments", Journal of Cleaner Production, 65(0): p. 418-423.

Whiting, D. (1981). "Rapid determination of the chloride permeability of concrete", in Final Report No. FHWA-RD-81/119, Portland Cement Association, Federal Highway Administration.

Wild, S. , Khatib, J. M., and Jones, A. (1996). "Relative strength, pozzolanic activity and cement hydration in superplasticised metakaolin concrete", Cement and Concrete Research, 26(10): p. 1537-1544.

Xinying Lu, Cuiling Li, and Zhang, H. (2002). "Relationship between the free and total chloride diffusivity in concrete", Cement and Concrete Research,. 32(2): p. 323-326.

Yang, C. C. and Cho, S. W. (2003). "An electrochemical method for accelerated chloride migration test of diffusion coefficient in cement-based materials", Materials Chemistry and Physics,. 81(1): p. 116-125.

Yu, L. H., Ou, H., and Lee, L. L. (2003). "Investigation on pozzolanic effect of perlite powder in concrete", Cement and Concrete Research,. 33(1): p. 73-76.

$\mathrm{Yu}$,L.H., Ou, H., and Zhou, SX. (2010). "Influence of Perlite Admixture on Pore Structure of Cement Paste", Advanced Materials Research,. 97: p. 552-555. 